\title{
Against Emergent Dualism
}

\author{
Brandon Rickabaugh \\ brandon_rickabaugh@baylor.edu \\ www.brandonrickabaugh.com \\ Forthcoming in The Blackwell Companion to Substance Dualism. \\ Edited by Johnathan Loose, Angus Menuge, and J. P. Moreland. \\ Oxford, UK: Wiley Blackwell, 2018.
}

\section{Introduction}

Materialism permeates philosophy of mind. Yet, increasing difficulties are triggering dissent. ${ }^{1}$ William Hasker's insightful yet underappreciated work in the philosophy of mind is representative. Hasker does not favor the recent turn toward non-reductive physicalism either. Rather, his argument from the unity of consciousness entails SUBSTANCE DUALISM. Additionally, Hasker maintains that the soul is an emergent substance, a view he calls EMERGENT DUALISM. ${ }^{2}$ Hasker's criticisms of materialism are formidable, and his unity of consciousness argument deserves considerable attention. Still, EMERGENT DUALISM faces difficulties. I argue that EMERGENT DUALISM is not more attractive than non-emergent versions of SUBSTANCE DUALISM as Hasker suggests. I raise several new problems for EMERGENT DUALISM that non-emergent versions of SUBSTANCE DUALISM evade.

\section{What is Emergent Dualism?}

According to SUBSTANCE DUALISM the following is true,

SUBSTANCE DUALISM: Human persons are not identical to any physical body, but consist of a physical body and a non-physical substantial soul.

\footnotetext{
${ }^{1}$ See for example, The Waning of Materialism, edited by Robert Koons and George Bealer (Oxford: Oxford University Press, 2010); After Physicalism, edited by Benedikt Paul Göcke (Notre Dame, ID: University of Notre Dame Press, 2012); and Contemporary Dualism: A Defense, edited by Andrea Lavazza and Howard Robinson (New York, NY: Routledge, 2013).

${ }^{2}$ Although a minority view, Hasker is not alone. Other advocates of similar if not identical views include, Eric LaRock, "From Biological Naturalism to Emergent Subject Dualism," Philosophia Christi 13 (1) (2013): 97-118; Dean Zimmerman, "From Experience to Experiencer," in The Soul Hypothesis, edited by Mark Baker and Stewart Goetz (London: Continuum Press 2011): 168-96; and John Eccles and Karl Popper, The Self and Its Brain (London: Routledge, 1993).
} 
The term 'consist' leaves room for various views, according to which a human person is the soul, or is an embodied soul. ${ }^{3}$ Hasker adopts a more specific version of SUBSTANCE DUALISM:

EMERGENT DUALISM: (a) Human persons are not identical to any physical body, but consist of a physical body and a non-physical substantial soul, and (b) the human soul is naturally emergent from and dependent on the structure and function of a living human brain and nervous system. ${ }^{4}$

It is (b) that makes Hasker's view unique. Other types of SUBSTANCE DUALISM reject (b). What then is the nature of emergence and the emergent soul?

\subsection{The Nature of Emergence \& Emergent Dualism}

According to the doctrine of emergence, when the parts of a system are arranged in the right way their collective activity brings something new into existence. The new emergent entity is not reducible to the parts of the system it came from. It is distinct in terms of its structure and causal powers. Hasker embraces four categories of emergence corresponding to various properties, events, and substances.

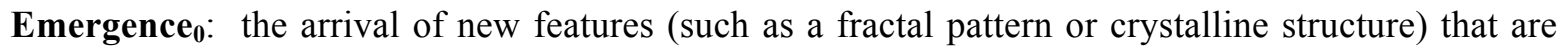
logical consequences of a new arrangement of lower-level elements. ${ }^{5}$

Emergence $_{1 \mathbf{a}}$ : the arrival of higher-level features (such as solidity, liquidity and transparency) resulting from causal interactions among lower-level elements. ${ }^{6}$

Emergence $_{\mathbf{1 b}}$ : the arrival of new modes of behavior, emergent causal powers (powers the brain has) describable only in terms of the operations of new emergent laws (systems of interaction between atoms and molecules of the brain) resulting from causal interactions among lower-level elements. ${ }^{7}$

\footnotetext{
${ }^{3}$ For more on these distinctions, see, C. Stephen Evans and Brandon Rickabaugh, "What Does It Mean to Be a Bodily Soul?" Philosophia Christi 17 (2) (2015): 315-330.

${ }^{4}$ William Hasker, "The Dialect of Soul and Body," Contemporary Dualism: A Defense, edited by Andrea Lavazza and Howard Robinson (New York, NY: Routledge, 2014), 215-16.

${ }^{5}$ Hasker, The Emergent Self (Ithaca, NY: Cornell University Press, 1999), 173.

${ }^{6}$ Ibid., 173-174.

${ }^{7}$ Ibid., 174; see also, Hasker, "On Behalf of Emergent Dualism," In Search of the Soul: Four Views on the Mind-Body Problem. Edited by Joel B. Green and Stuart L. Palmer. Downers Grover, IL: InterVarsity Press, 2005), 77.
} 
Emergence $_{2}$, the arrival of a new entity (a nonphysical substantial soul) with libertarian freedom (powers of the soul), resulting from, but not consisting in, the proper configuration of a material substrate. ${ }^{8}$

According to Hasker, emergent causal powers are, 'already implicit in the physical 'stuff,' otherwise their emergence would sheerly be magical." ${ }^{9}$ They only become detectible once the base elements are appropriately arranged. It is at emergence ${ }_{2}$ that human persons appear, as Hasker explains,

emergentism implies that consciousness, thought, rational volition, and so on make their appearance naturally as a result of the structure and functioning of the human brain and nervous system...emergentists do not view the mind and its powers as being, as it were, injected from outside into the human biological system. Instead, the soul appears naturally, given the appropriate physical organization and function of the body and brain. ${ }^{10}$

It is imprecise to say that, "the soul appears naturally." Perhaps Hasker means to say the soul regularly appears under the right circumstances. He cannot mean "in a way explicable by naturalism." Hasker is committed to a kind of panpsychism - protopanpsychism - that has historically rivaled naturalism (more on this below). ${ }^{11}$ Secondly, it seems odd that a physical object generates the soul. ${ }^{12}$ According to Hasker's view, the brain's mental potentialities (which I find perplexing) and the fact that causal dispositions are as much a part of a things essence as its categorical properties, means that the soul is generated by a psycho-physical object. This is why many physicalists avoid emergentism. ${ }^{13}$

Lastly, according to EMERGENT DUALISM mental properties and mental events emerge from the brain. ${ }^{14}$ They are distinct from and not determined by the operations of the brain or its physical properties. ${ }^{15}$ Additionally, novel causal powers associated with these mental properties and mental events emerge. This makes EMERGENT DUALISM a type of protopanpsychism. These novel causal powers

\footnotetext{
${ }^{8}$ Hasker, The Emergent Self, 177; and, William Hasker, "The Emergence of Persons," A Companion to Christianity and Science, ed. James Stump and Alan Padgett (London: Blackwell, 2012), 483.

${ }^{9}$ Hasker, "Emergent Dualism: A Challenge to a Materialist Consensus," in What About the Soul? Neuroscience and Christian Anthropology, edited by Joel B. Green (Nashville, TN: Abington Press, 2004), 112.

${ }^{10}$ William Hasker, "Why Emergence?," Ashgate Research Companion to Theological Anthropology, edited by Joshua Farris and Charles Taliaferro (Burlington, VT: Ashgate, 2015), 152.

${ }^{11}$ For en excellent historical treatment see, David Skbina, Panpsychism in the West (Cambridge, MA: MIT Press, 2005).

${ }^{12}$ See for example, William Hasker, "Is Materialism Equivalent to Dualism?" in After Physicalism, edited by Benedikt Paul Göcke (Notre Dame: University of Notre Dame Press, 2012), 196. I quote the relevant passage below in 1.2.2.

${ }^{13}$ It is worth noting that those who adopt an Aristotelian/Thomistic view of chemical change and substances have no reason to adopt the mechanistic and emergent view. See, for example, Richard J. Connell, Substance and Modern Science (Houston, TX: Center for Thomistic Studies, 1988).

${ }^{14}$ Hasker, "Why Emergence?", 157.

${ }^{15}$ Hasker, "The Dialectic of Soul and Body," 217.
} 
also commit Hasker to the incompleteness of physics and the rejection of the causal closure of the physical. Most importantly, the non-physical, substantive, soul also emerges from the brain and brain stem. So, what is the nature of the emergent soul?

\subsection{The Nature of the Emergent Soul}

\subsubsection{The Emergent Soul as the Person, the Conscious Self}

The soul of EMERGENT DUALISM is the conscious self. It thinks, reasons, feels emotion, makes decisions, and is at the core of what we mean by 'person." ${ }^{16}$ The emergent soul has mental experiences and exercises these emergent causal powers. ${ }^{17}$ Hence, certain facts about the soul wholly ground facts about personhood, consciousness, intellect, affect, and will. This must be the case as Hasker maintains it is metaphysically possible for the soul to exist apart from the body. This is standard SUBSTANCE DUALISM.

\subsubsection{The Emergent Soul as an Immaterial, Unified, Substance}

The emergent soul is immaterial, as it has no material parts. It is a substance with its own causal powers. Additionally, the soul is unified, although isn't always clear what Hasker means by this. "The self of emergent dualism," says Hasker, "is not a Cartesian soul: it is generated by the functioning of a physical object and is itself spatially located, and it is not simple in the way that a Cartesian soul is simple." ${ }^{18}$ Hasker speaks of the simplicity of the soul as "an undivided whole."19 Elsewhere, he states

...the self that is the subject of experiences must function as an undivided unity and not as a system of parts. But this does not immediately carry with it all the freight traditionally attached to metaphysical doctrines of the "simplicity of the soul.",20

It appears that Hasker's emergent soul is not mereologically simple, but only an undivided whole. In fact, the soul, according to Hasker, is a substance that could be, and in some cases is, divided. Hasker states,

I have repeatedly argued, for example, that the emergent self could under certain circumstances be divided - for instance, by the fission of the generating organism. (Arguably the famous cases of "brain bisection" through commissurotomy constitute partial examples of this possibility.) ${ }^{21}$

${ }^{16}$ William Hasker, "On Behalf of Emergent Dualism", in In Search of the Soul: Four Views of the Mind-Body Problem, edited by Joel B. Green and Stuart L. Palmer (Downers Grover, IL: InterVarsity Press, 2005), 78.

${ }^{17}$ Hasker, "Why Emergence?", 159.

${ }^{18}$ Hasker, "Is Materialism Equivalent to Dualism?", 196.

${ }^{19}$ Hasker, "Why Emergence?", 159.

${ }^{20}$ Hasker, "Is Materialism Equivalent to Dualism?”, 187. 
These remarks are in tension with a more recent statement of Hasker's:

...the self, the subject of experience, cannot be a complex physical object such as the human body or brain. Instead it must be a simple substance, one that has no parts that are themselves substances, and which cannot be divided into parts. ${ }^{22}$

Taken together, these remarks are perplexing. Hasker holds that the soul is a unified whole, but is he talking of functional unity or the metaphysical unity had by a mereologically simple substances? His early remarks suggest not. However, his argument from consciousness, his recent endorsement of David Barnett's simple argument, and the quotation immediately above, strongly suggest that Hasker holds that the soul is mereologically simple. ${ }^{23}$ It has no separable parts. This is no trivial point, as this plays a significant role in an objection below.

\subsubsection{The Emergent Soul as Metaphysically and Developmentally Dependent}

Lastly, Hasker thinks of his view as a type of integrative dualism. The soul and body form a completely integrated unity. The soul is nomologically dependent on the brain and brain stem for its existence and development. "The mind/soul," Hasker explains, "is both generated and sustained by the biological organism, and its activities are subserved and enabled by the function of the organism." ${ }^{\text {"T }}$ The soul is developmentally dependent on the brain for the gradual development of its capacities in accordance with the developing brain and nervous system. ${ }^{25}$

\subsection{Is the Emergent Soul Unique?}

According to Hasker, EMERGENT DUALISM does not have the problems of non-emergent versions of SUBSTANCE DUALISM. ${ }^{26}$ However, Hasker's view of the soul does not substantially differ from non-emergent forms of SUBSTANCE DUALISM. Consider, for example Descartes' view. Like Hasker, Descartes maintained that the soul is a unified, immaterial, substance, capable of being supernaturally sustained by God apart from its body. Hasker's account of the uniting of the soul with its

${ }^{21}$ Hasker, Ibid, 187. See also, The Emergent Self, ch. 7; and "Persons and the Unity of Consciousness" in The Waning of Materialism, edited by Robert Koons and George Bealer (Oxford: Oxford University Press, 2010): 175-90.

${ }^{22}$ William Hasker, "Do my Quarks Enjoy Beethoven?" In Neuroscience and the Soul: The Human Person in Philosophy, Science, and Theology, edited by Thomas M Crisp, Steven L Porter, Gregg Ten Elshof (Grand Rapids, MI: William B. Eerdmans Publishing Company, 2016).

${ }^{23}$ See, for example, Hasker, "Do my Quarks Enjoy Beethoven?"

${ }^{24}$ Hasker, "On Behalf of Emergent Dualism", 79.

${ }^{25}$ Hasker, "The Dialect of Soul and Body," 216.

${ }^{26}$ Hasker, The Emergent Self, chapter 6. 
resurrection body is more Cartesian than emergentist, as the renewed soul is infused into a new body. ${ }^{27}$ Perhaps Hasker thinks his view departs from Descartes regarding the strong interactive dependency between soul and body. However, this is mistaken.

According to Descartes it is metaphysically possible, by the miraculous intervention of God, for the soul to exist without the body. This is far different than thinking the soul and body exist separately. The mere metaphysical possibility of separation is all Descartes' arguments conclude. ${ }^{28}$ Descartes adamantly rejects the dualism of Plato, which sees the soul and body as entirely separate. The soul, says Descartes, does not simply reside in the body "as a pilot resides in a ship," but rather forms a kind of natural unity "most closely joined" and "as if intermixed" with it. ${ }^{29}$ Descartes' view has more in common with scholastic-Aristotelian theories of soul-body union than is often portrayed. ${ }^{30}$ For Descartes there is no "ghost in the machine." ${ }^{31}$ He refers to the soul as a "substantial form", ${ }^{32}$ and "substantially united",33 with the body. Descartes' view, like Hasker's, is that the mind and body are intimately connected.

Hasker's view differs little from non-emergent SUBSTANCE DUALISM, which he admits can account for the strong dependence of the mind on the brain. ${ }^{34}$ Where Hasker's view does diverge significantly has to do with the origin of the soul. Descartes, like Augustine and Aquinas, held that God creates the soul. ${ }^{35}$ Hasker, however, thinks the soul naturally emerges from a complex arrangement of matter. That is, according to EMERGETN DUALISM, there are psycho-physical laws that determine when a soul comes into existence. These laws kick in as it where, when an aggregate of matter reaches the necessary level of complexity. It is not clear if these laws are necessary laws or contingent laws. However, I am persuaded by Rasmussen's argument in this volume that no psycho-physical laws are necessary.

I am convinced that Hasker's preference for EMERGENT DUALISM boils down to aesthetic considerations. He seems to think it is aesthetically more pleasing not to have God intervening billions of

${ }^{27}$ Hasker, Ibid, 135 .

${ }^{28}$ Both versions of the argument appear in Descartes, Meditations on First Philosophy, Sixth Meditation. The first version is in CSM II 54, and the second version appears in CSM II 59. All references to Descartes work are from Descartes Selected Philosophical Writings, translated by John Cottingham, Robert Stoothoff, and Dugald Murdoch (Cambridge: Cambridge University Press, 1988), standardly referred to as CSM.

${ }^{29}$ René Descartes, Meditations on First Philosophy, Sixth Meditation, 81; (CSM II 56). See also Discourse on Method 1637, part 5: 59 (CSM I 141), and Meditations on First Philosophy, Objections and Replies 228 (CSM II 160).

${ }^{30}$ See for example, Paul Hoffman, "The Unity of Descartes' Man," The Philosophical Review 95 (1986): 339-369. For a critical treatment of Hoffman, see Marleen Rozemond, Descartes's Dualism (Cambridge: Harvard University Press, 1998). For a response to Rozemond, see Justin Skirry, Descartes and the Metaphysics of Human Nature (London and New York: Thoemmes-Continuum Press, 2005).

${ }^{31}$ The "ghost in the machine" is a phrase coined by Gilbert Ryle to describe Descartes' mind-body dualism (The Concept of Mind, 1949). The phrase was intended to portray the mysterious notion of mind/brain interaction, but to this day is often mistaken for an accurate statement of Descartes' view.

${ }^{32}$ René Descartes, Letter to Regius, CSM III, 207-208.

${ }^{33}$ René Descartes, Letter to Mesland, CSM III 243.

${ }^{34}$ Hasker, The Emergent Self, 155 and 157.

${ }^{35}$ See for example, Descartes, Discourse on Method, 141; Aquinas, Summa Contra Gentiles, 2. 87, 3 and 4. 
times creating souls ex nihilo. However, Hasker has God intervening just as many times to directly preserve the disembodied soul in an intermediate state. If God has to do that, what is so aesthetically displeasing about God intervening to create souls ex nihilo? It is arguable that being able to create something ex nihilo is a great-making property. To think matter has this power is theologically bizarre.

\section{Problems for Emergent Dualism}

Hasker's view has been met with interesting objections. ${ }^{36}$ In this section I introduce problems unique to EMERGENT DUALISM that non-emergent versions of SUBSTANCE DUALISM evade.

\subsection{A Problem for Emergence \& Explanatory Power}

Dallas Willard argued that John Searle's use of emergence to explain consciousness is problematic. ${ }^{37}$ I suggest some of these objections apply to Hasker's view. Willard states,

we do have a pretty good story about what the atoms, molecules, etc., do to produce solidity, liquidity, boiling of the $\mathrm{H}_{2} \mathrm{O}$. But in the case of the brain and its alleged emergent properties of consciousness, there is just no story at all. At best we have a rather crude set of brute correlations indirectly established. ${ }^{38}$

Hasker admits that the emergence of new laws and presumably consciousness is, "a far cry from the 'emergence' of solidity and the like, which is based entirely on the operation of the micro-elements according to the standard laws of physics and chemistry." 39 There remains an explanatory gap between how molecular states of $\mathrm{H}_{2} \mathrm{O}$ produce solidity and how brain states produce mental states, much less a soul. Willard rightly points out, "There is nothing about brain cell activity that would naturally associate it with intentionality, moods, qualia or subjectivity as these are present on the mental side of our life."40 Of course, Hasker is in agreement with Willard that the brain cannot be conscious. Why think the problem does not extend to the emergence of the soul from a brain?

\footnotetext{
${ }^{36}$ For example, Patrick Lee and Robert George argue that reflective self-awareness, universal concept formation, abstract reasoning, and free will must be independent of and transcend matter, which means they could not have emerged from lower forces (Patrick Lee and Robert P. George, Body-Self Dualism in Contemporary Ethics and Politics (New York: Cambridge University Press, 2008), chapter 2). Antonella Corradini argues Hasker's view is incompatible with holding that consciousness is dependent on purely material processes and that there are novel emergent powers at the level of consciousness (Antonella Corradini, "Emergent Dualism", Psycho-Physical Dualism Today: An Interdisciplinary Approach, edited by Alessandro Antonietti, Antonella Corradini, and Jonathan Lowe (Lanham, MD: Lexington Books, 2008), 202-203).

${ }^{37}$ Dallas Willard, "Non-Reductive and Non-Eliminative Physicalism?" Unpublished Paper. Available online at (http://www.dwillard.org/articles/artview.asp?artID=48).

${ }^{38}$ Ibid.

${ }^{39}$ Hasker, "Do My Quarks Enjoy Beethoven?” forthcoming.

${ }^{40}$ Willard, "Non-Reductive and Non-Eliminative Physicalism?"
} 
Notice, this is an in-principle problem, not one that merely reflects the current state of our knowledge. When emergent properties were characterized epistemically, they were described as those properties for which an exhaustive, God's eye view of the subvenient base would not predict or be able to explain. This is true today even though emergent entities are characterized ontologically. They are so unique, that all one can say is that when matter reaches "the right stage" of complexity, emergence obtains. ${ }^{41}$ However, there is no informative, non-circular way to specify what "the right stage" is amounts to. All one can say is it is the way things need to be for emergence to occur. But, this borders on being tautological, rather than informative: when things are arranged so that emergence occurs, emergence occurs.

Moreover, Willard argues,

A striking lack of parallelism between the $\mathrm{H}_{2} \mathrm{O}$ cases and the brain is the following: We have absolutely no theory independent knowledge that the brain has properties Searle assigns to it, as we do that the water is boiling, solid, or liquid. ${ }^{42}$

Likewise, we have absolutely no theory independent knowledge that the soul emerges from the brain. Much of Hasker's case for EMERGENT DUALISM rests on emergence ${ }_{2}$, which is made plausible by the applicability of emergence e $_{1}$ mental properties. Willard has given us reason to question that emergence $_{1}$ includes mental properties, and these arguments can be applied to emergence 2 . This raises concerns for Hasker's view. Talk of emergence does not illuminate the issue of the origin of the soul, as the comparison of $\mathrm{H}_{2} \mathrm{O}$ exhibiting solidity is "a far cry" from the brain producing a soul. It fact, I am inclined to think that talk of emergence is merely a label for the problem to be solved and not itself a solution.

Lastly, it seems that EMERGENT DUALISM lacks the kind of explanatory power it is intended to provide. Dean Zimmerman, an advocate of EMERGENT DUALISM, states,

The details of the mechanism by which brains generate souls remain, admittedly, as speculative as the search for a special conscious particle or a precisely demarcated conscious chunk of brain matter. $^{43}$

\footnotetext{
${ }^{41}$ William Hasker, "On Behalf of Emergent Dualism”, 76.

${ }^{42}$ Willard, "Non-Reductive and Non-Eliminative Physicalism?"

${ }^{43}$ Dean Zimmerman, "From Experience to Experiencer", in The Soul Hypothesis: Investigations into the Existence of the Soul, edited by Mark C. Baker and Stewart Goetz (New York, NY: Continuum, 2011), 195.
} 
I think Zimmerman is correct. Consequently, we have reason to be suspicious of Hasker's claim that EMERGENT DUALISM is more scientifically informed than non-emergent forms of SUBSTANCE DUALISM. If the brain produces consciousness, then there is no illumination regarding the origin of consciousness, as emergence is not illuminating but mysterious. Moreover, If emergentism includes the view that there are necessary psycho-physical laws, then I can't see how anything from science could in principle favor emergentism over the view that the psycho-physical laws are contingent.

\subsection{An Emergent Problem of the Many}

Here I apply Peter Unger's mental problem of the many for materialism to EMERGENT DUALISM. ${ }^{44}$ The argument begins by noting the composition of material objects. A chair, for example, is composed of billions of atomic simples arranged in the shape of a chair. However, the chair could have been made slightly smaller and thereby would have been composed of slightly less atomic simples. It seems that a chair composed of billions of atomic simples actually has overlapping parts or sub-regions that are themselves billions of atomic simples arranged in the shape of slightly smaller chairs. Therefore, for any chair there are actually billions of sub-chairs overlapping one another. We might not talk this way, but this is true of any macro-material object. Of course, on a mechanistic view such as Hasker's, this includes human brains.

This can be applied to an argument against EMERGENT DUALISM:

P1. If EMERGENT DUALISM is true, then wherever there is a properly complex arrangement of parts of kind- $k$ a soul emerges.

P2. A brain is an aggregate of billions of parts of kind- $k$ with many sub-regions of overlapping parts of kind- $k$.

P3. Therefore, if EMERGENT DUALISM is true, there should be multiple souls emergent from any one brain.

Notice that P1 is a commitment of Hasker's view. As already explained, P2 is a commitment of Hasker's regarding all macro-material objects. A properly complex arrangement of parts of kind- $k$ just is a living properly functioning human brain. Like the table the brain could have been just a little smaller in billions of ways and still remained a brain. These billions of overlapping parts are all within any normal brain. Hence, P2 is justified, and the conclusion logically follows. Consequently, EMERGENT DUALISM entails the incredible notion that from my brain emerge billions of souls with experiences just like mine,

\footnotetext{
${ }^{44}$ Peter Unger, "The Mental Problems of the Many", in Oxford Studies in Metaphysics, vol. 1, edited by Dean Zimmerman (Oxford: Clarendon Press, 2004): 196-222.
} 
thinking my thoughts. ${ }^{45}$ This absurd. As those such as Brentano, ${ }^{46}$ and Chisholm ${ }^{47}$ have argued, this conclusion is incompatible with the basic awareness I have of myself as a single unified self.

One might object that what is true of chairs is not true of brains. Perhaps there is some specific number of parts necessary for kind- $k$ such that a brain is not really a mass of overlapping smaller brains. There is empirical evidence that seriously undermines this notion. There are cases of people who function normally yet, either congenitally or due to surgery, are missing parts and even significant regions of their brain. For example, hemispherectomy involves the removal of parts of a hemisphere (functional hemispherectomy) or even an entire hemisphere (anatomical hemispherectomy). Many of these patients recover normal cognitive function. ${ }^{48}$ Secondly, studies by John Lorber of patients cured of hydrocephalus revealed that 60 of the 600 patients had ventricular fluid occupying at least $95 \%$ of their cranial capacity! In spite of missing so much of their brain, and to the astonishment of neuroscientists, "half of Lorber's 60 cases were of above normal intelligence." ${ }^{49}$ There are in fact sub-regions of the brain that have all the necessary parts and relations to function as a brain. In another context Hasker states that "presumably two generating bodies - two distinct brains and nervous systems - cannot occupy the same space..."50 However, Hasker simply assumes this, and I have given reason to doubt this presumption.

Perhaps Hasker can place a restriction on (P1), such that a complex arrangement of parts is necessary for the emergence of the soul, but not sufficient. It seems Zimmerman has something like this in mind where he writes,

I suppose that the following hypothesis is more likely: that many overlapping sets of events occur in the brain, none of which is the minimal cause of the soul's ongoing existence, nor the single cause of its overall phenomenal state. With many overlapping patterns of neural firings, each lawfully sufficient for the existence of a soul with the same phenomenal states, there could still be just one soul, its existence and phenomenal state simply overdetermined. There need be no vagueness about which activities in the brain generate the subject of consciousness - in fact, on

${ }^{45}$ This generates a problem most philosophers of mind take as a serious objection to other views, called the Too Many Thinkers problem. For a helpful introduction to the traditional Too Many Thinkers objection see, Eric Olson, What Are We? A Study in Personal Ontology (Oxford: Oxford University Press, 2007), 29-39.

${ }^{46}$ Franz Brentano, Psychology from an Empirical Standpoint (London: Routledge \& Kegan Paul, 1973), 160.

${ }^{47}$ Roderick Chisholm, The First Person: An Essay on Reference and Intentionality (Minneapolis, MN: University of Minnesota Press, 1981), 86-88.

${ }^{48}$ For a detailed account of one amazing case see, Antonia Battro, Half a Brain is Enough: The Story of Nico (Cambridge University Press, 2001). For a wide study see, Ahsan N.V. Moosa, et all, "Longitudinal Seizure Outcome and Prognostic Predictors after Hemispherectomy in 170 Children”, Neurology 80 no. 3 (January 2013): 253-260.

49 Donald R. Forsdyke, "Wittgenstein's Certainty is Uncertain: Brain Scans of Cured Hydrocephalics Challenge Cherished Assumptions", Biological Theory (forthcoming) First online: 24 July 2015. Also, see Roger Lewin, "Is Our Brain Really Necessary?" Science, New Series, 210, no. 4475 (December 1980): 1232-1234.

${ }^{50}$ William Hasker, "Jagewon Kim's Rejection of Substance Dualism", in Philosophy and the Christian Worldview: Analysis, Assessment and Development, edited by David Werther and Mark D. Linville (London: Continuum, 2012), $224-25$. 
this supposition, many precise (and largely overlapping) events are equally responsible — nor about how many there are. ${ }^{51}$

This reply might work regarding neural activities. However, the problem I have suggested is not with the vagueness of activities, but of the brain itself. Assume the emergent laws Zimmerman stipulates. It is still problematic that a brain has a vast number of sub-regions each of which is sufficient for the emergence of the soul. In this way, my argument sidesteps views such as Trenton Merricks that reject the notion of overlapping brains. ${ }^{52}$ Even if Merricks is right that there are not multiple overlapping brains, still you have multiple functions that are individually sufficient for the emergence of a soul (if any of them are). The problem isn't at the level of the laws, but at the level of the complex arrangement of atomic simples and their functions. Any restriction Hasker might place would be ad hoc. Perhaps Hasker might dig his heels in and assert that only one of the configurations yields a soul. This, I will argue, creates a sorites problem.

\subsection{A Sorites Problem}

Recall that according to EMERGENT DUALISM the soul emerges once an aggregate of matter is arranged in the right way. Hasker writes, “...prior to the emergence [of the soul] there was only an aggregate of simples, even if the arrangement of the simples was very similar to that of the body parts of a person." $"$ As previously argued, there are problems for how to understand what "the right way" could mean. Here is an addition problem. Consider an aggregate of matter arranged in such a way as to be a properly functioning brain and central nervous system, the number of parts arranged in the right way required for a soul to emerge is $n$. Consequently, there is some subset of those parts - atomic simplesand their arrangement such that they are sufficient, not for a soul to emerge, but for an organ just short of a brain to exist. Now, suppose God has this organism and is adding one by one and activating atomic simples until being just shy of $\mathrm{n}$ by one simple $(n-1)$. At the moment God adds the final atomic simple, the relevant emergence ${ }_{2}$ laws activate, and the soul emerges.

Here is the problem. There is no metaphysical significance between having $n-1$ atomic simples behaving in a certain way and having $n$ atomic simples behaving in a certain way. The two cases do not differ in a metaphysically significant way at all. However, according to EMERGENT DUALISM the soul comes into existence once $n$ is added to $n-1$. Hasker's view is committed to attributing a quite a significant degree of power to the addition of one atomic simple.

\footnotetext{
${ }^{51}$ Zimmerman, "From Experience to Experiencer", 195.

${ }^{52}$ See, Trenton Merricks, Objects and Persons (Oxford: Oxford University Press, 2001).

${ }^{53}$ Hasker, "Is Materialism Equivalent to Dualism?", 185.
} 
How could a defender of EMERGENT DUALISM reply? Holding out for an empirical discovery to give us the precise number or range for $n$ required for a soul to emerge wouldn't change the metaphysical problem. Perhaps one could reply that it isn't merely $n$ number of atomic simples that does all the work, but that we also need the correct arrangement of $n$ atomic simples. This seems to be what Hasker has in mind. This does relieve the number of atomic simple of doing all the metaphysical work. But is this good enough? I think the answer is, no. Notice that the aggregate of $n-1$ atomic simples is already structured. At the moment the final atomic simple is added the structure is complete. It is still the addition of the final atomic simple to the aggregate that does all the work. It is simply added in the right place. EMERGENT DUALISM is left with the problem of attributing a significant degree of power to the addition of one atomic simple.

\subsection{A Combination Problem for EMERGENT DUALISM}

A view gaining popularity among materialism dissenters is called panpsychism, according to which fundamental physical entities (perhaps quarks and photons) have conscious experience and bind together to form conscious human persons. Philosophers such as David Chalmers think panpsychism and protopanpsychism enjoys the advantages of materialism and dualism without being encumbered by the problems either face. ${ }^{54}$ However, panpsychism faces the combination problem. Roughly, the problem is to explain just how the experiences of fundamental physical entities combine to yield the kind of conscious experience we have every day. ${ }^{55}$

The combination problem arises in virtue of attributing certain powers to matter. I think EMERGENT DUALISM faces a similar problem. " "The mind/soul," Hasker explains, " is both generated and sustained by the biological organism, and its activities are subserved and enabled by the function of the organism." ${ }^{57}$ Consequently, EMERGENT DUALISM is maintains that a unified nonphysical substance emerges from a physical aggregate of parts. To understand the problem, recall the dependence relation between body and soul Hasker is committed to. He states,

\footnotetext{
${ }^{54}$ See David Chalmers, "Panpsychism and Protopanpsychism", in Consciousness in the World: Perspectives on Russellian Monism, edited by Torin Alter and Yujin Nagasawa (Oxford: Oxford University Press, 2015): 246-76.

${ }^{55}$ David Chalmers, "The Combination Problem for Panpsychism" forthcoming.

${ }^{56}$ For a more detailed treatment of this argument and what I take to be it's positive contribution to the ontology of human persons see, Brandon L. Rickabaugh, "Emergent Dualism Cannot Save the Soul, But Neo-Aristotelianism Might", forthcoming.

${ }^{57}$ Hasker, "On Behalf of Emergent Dualism”, 79.
} 
My view is that the conscious field is indeed divided as a consequence of the supporting organism's being divided, and this seems an entirely plausible view, once we grant the possibility of the field's being generated by the organism in the first place. ${ }^{58}$

Note, this implies a grounding relation between body and soul. Accordingly, the body is ontologically more fundamental that the soul in certain respects. According to standard accounts, $A$ s are ontologically more fundamental than $B \mathrm{~s}$, in the relevant sense, if facts about the existence of $B \mathrm{~s}$ are grounded in facts about $A \mathrm{~s} .{ }^{59}$ In this case, facts about the soul (being divided) are grounded in facts about the body (the organism being divided). So, what facts about the soul are grounded in facts about the body? It seems that at least structural facts about the body ground structural facts about the soul. The body splits, so the soul splits. How is it then that the structure of the soul is such that it is a unified whole when the body, which grounds the structural facts of the soul, is not itself unified?

Let's return to the combination problem for panpsychism. Regarding panpsychism, Hasker writes,

What we need is a single mind, and a single field of conscious awareness, for each sentient being...Panpsychism leaves this need unmet, and we would still need an explanation of the process by which those bits of mind-dust are fused into a single conscious mind. But given that this need would remain, not much is gained by postulating the mind-dust to begin with. ${ }^{60}$

Quoting John Searle, Hasker states that what we need to know is "how the brain produces the peculiar organization of experiences that express the existence of the self. ${ }^{, 61}$ Of course Hasker's view does not face the same combination problem as panpsychism as it does not attribute consciousness to bits of matter. ${ }^{62}$ But Hasker's view, which is a type of protopanpsychism, faces a similar problem.

EMERGENT DUALISM faces the problem explaining how bits of non-conscious matter combine to constitute mental properties and produce a conscious soul. More precisely, EMERGENT DUALISM needs an explanation for the process by which a unified, immaterial, substance, with a

${ }^{58}$ Hasker, "Reply to My Friendly Critiques," Philosophia Christi 2 (2) (2000), 103.

${ }^{59}$ According to Jonathan Shaffer, ' $x$ is fundamental' just means that 'nothing grounds $x$ ', while ' $x$ is derivative' just means that 'something grounds $x$.' See, Jonathan Schaffer, "On What Grounds What" in David Manley, David J. Chalmers \& Ryan Wasserman (eds.), Metametaphysics: New Essays on the Foundations of Ontology (Oxford: Oxford University Press, 2009), 373. See also, Gideon Rosen, "Metaphysical Dependence, Grounding and Reduction," Modality: Metaphysics, Logic, and Epistemology, edited by Bob Hale and Aviv Hoffmann (Oxford: Oxford University Press, 2010): 109-135; and Kit Fine, "Guide to Grounding," Metaphysical Grounding: Understanding the Structure of Reality, edited by Fabrice Correia and Benjamin Schnieder (Cambridge: Cambridge University Press, 2012): 37-80.

${ }^{60}$ William Hasker, "Do My Quarks Enjoy Beethoven?" Forthcoming.

${ }^{61}$ John Searle, "The Self as a Problem in Philosophy and Neurobiology" in John Searle, Philosophy in a New Century: Selected Essays (Cambridge University Press, 2008), 136.

${ }^{62}$ See David Chalmers, "The Combination Problem for Panpsychism" forthcoming. 
complex organized system of mental properties, that is mereologically simple emerges from a material organism composed of billions of separable parts. It seems equally mysterious and equally problematic as to how a brain could be organize in such a way as to produce a soul. This seems more difficult than the

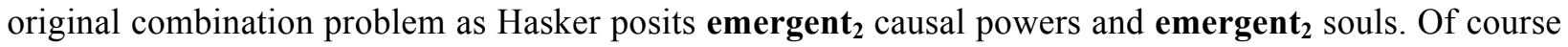
souls seem to solve the binding problem and the unity of consciousness in general. However, the cost of EMERGENT DUALISM is just as great as the cost of panpsychism insofar as the emergence of a soul is just as mysterious and perhaps more problematic than getting conscious minds from conscious matter.

Perhaps one could reply that I've merely shifted the burden of proof onto the defender of EMERGENT DUALISM, and this isn't itself a reason to reject the view. Fair enough, although I've argued this is a heavy burden. Without a plausible solution EMERGENT DUALISM is at least unmotivated.

However, we can strengthen the objection beyond exposing a weakness in Hasker's view to a substantive defeater. The argument I have in mind is as follows:

P1. If EMERGENT DUALISM is true, then facts about the unity of soul are wholly grounded by facts about the unity of the brain.

P2. The facts about the unity of the soul cannot be wholly grounded by facts about the brain.

P3. Therefore, EMERGENT DUALISM is false.

What can we say on behalf of this argument?

First, a distinction needs to be made regarding the nature of unity. That $x$ is functionally unified simply means the various parts of $x$ work together to accomplish some end. Artifacts and aggregates, for example, can be spoken of figuratively as functionally unified. But notice that since what is at work here is efficient causation, $x$ literally has no objective function. Rather, the parts of $x$ are assembled to imitate a function in the artificer's mind. This type of unity is external to $x$. However, metaphysical unity is distinct as it pertains to real (especially living) substances. Accordingly, $x$ is metaphysically unified just in case $x$ is a mereologically simple substance (substance that has no separable parts). Here the principle of unity is internal.

In defense of P1 consider that, as already noted, Hasker holds that emergent causal powers are "already implicit in the physical "stuff," otherwise their emergence would sheerly be magical." 63 The same thing should be said regarding features of the soul, such as unity. Recall that the only kind of unity a mere aggregate of parts can have is functional unity. However, the soul is metaphysically unified. Indeed,

${ }^{63}$ Hasker, "Emergent Dualism: A Challenge to a Materialist Consensus," in What About the Soul? Neuroscience and Christian Anthropology, edited by Joel B. Green (Nashville, TN: Abington Press, 2004), 112. 
Hasker's own argument from the unity of consciousness established this. ${ }^{64}$ So, in what way is the metaphysical unity of the soul implicit in an aggregate of parts that is merely functionally unified?

This issue is close to the concern raised by the binding problems of consciousness. Consciousness is unified in a variety of ways, but brains (at least on atomistic views, such as Hasker's) are not. Therefore, it seems difficult if not impossible for a brain to have a unified consciousness. ${ }^{65}$ The problem for EMERGENT DUALISM is that the brain is not metaphysically unified but atomistic and therefore cannot ground facts regarding the unity of the soul. There just is no fact regarding the metaphysical unity of the brain that could ground the fact that the soul is metaphysically unified. The brain just isn't metaphysically unified, but is, as Hasker says, an aggregate of atomic simples. Consequently, there is nothing true of the brain that can ground the truth of the metaphysical unity of the soul.

Here is another way to get at this objection. The unity of an aggregate, such as the brain, is one in which the relations among the parts are external relations. This is evident by the fact that the parts of the aggregate are separable parts. However, the unity of the soul is such that any differentiation of faculties or powers within the soul must stand in internal relations to the soul itself. This is evidenced by the fact that these inseparable parts - faculties of intellect, emotion, will, and so on — cannot exist outside the whole of which they are inseparable parts. In turn, this raises a new way to look at both the sorites and combination problems together. It is implausible that by adding a single atomic simple we get a new whole constituted by internal relations from a subvenient structured object (the brain) constituted by external relations.

What could be said in reply? Perhaps Hasker could avoid this problem by widening the gap between body and soul, such that the facts about the unity of the soul are not grounded in facts about the brain. This comes at a cost. Hasker would lose an argument he has endorsed for favoring EMERGENT DUALISM over non-emergent SUBSTANCE DUALISM. Namely, that his view makes better sense of the souls dependence on the brain in cases of commissurotomy and associative identity disorder. ${ }^{66}$ Secondly, widening the gap between body and soul pushes against the strong body-soul interaction EMERGENT DUALISM promises to provide. Again, Hasker would lose a motivating factor for his view. Widening the gap between body and soul is not an option. Consequently, EMERGENT DUALISM faces a combination problem.

\section{Conclusion}

I have argued that EMERGENT DUALISM faces a number of problems that non-emergent SUBSTANCE DUALISM evades. Perhaps these problems can be solved. Although, skeptical, I am

\footnotetext{
${ }^{64}$ Hasker, The Emergent Self, 122-46; and "Persons and the Unity of Consciousness", 181-83.

${ }^{65}$ Tim Bayne, Unity of Consciousness (Oxford: Oxford University Press, 2010), chapter 10.

${ }^{66}$ Hasker, "Persons and the Unity of Consciousness."
} 
curious how defenders of EMERGENT DUALISM might respond. Until then I think we have compelling reasons to reject EMERGENT DUALISM, reasons which do not extend to SUBSTANCE DUALISM. ${ }^{67}$

${ }^{67} \mathrm{I}$ am indebted to several helpful comments on the first version of the paper from J. P. Moreland, C. Stephen Evans, Stuart Goetz, and Joshua Rasmussen. 